\title{
Where is ENSO stress balanced?
}

\author{
Matthias Münnich*, J. David Neelin \\ Department of Atmospheric Sciences, Institute of Geophysics and Planetary Physics, University of California, \\ Los Angeles, CA 90095-1565, USA
}

Received 9 May 2003; revised 11 November 2003; accepted 20 November 2003

\begin{abstract}
The zonal surface torque budget associated with the tropical wind stress anomalies during El Niño/Southern Oscillation is analyzed. Mountain and surface stress torques over South America are found to play a prominent role. Local momentum change is negligible for 6 month averages allowing the balance among regional contributions to the torque anomalies to be compared. During El Niño, eastward torque anomalies over the central equatorial Pacific are largely compensated by westward anomalies elsewhere in the equatorial band, notably over South America. Torque anomalies over South America and the Pacific in latitude bands north and south of the equator are both westward and are not compensated within the band, implying an export of eastward momentum to higher latitudes. (c) 2003 Royal Meterological Society. Published by Elsevier Ltd. All rights reserved.
\end{abstract}

Keywords: El Niño/Southern oscillation; Angular momentum; Torque

\section{Introduction}

Wind stress anomalies in the equatorial central to western Pacific are fundamental to ocean-atmosphere feedbacks in El Niño/Southern Oscillation (ENSO). Westerly during the El Niño warm phase (easterly during the La Niña cold phase), these anomalies have received considerable attention in both observations (Harrison and Larkin, 1998; Deser and Wallace, 1990; Rasmusson and Carpenter, 1983; Wallace et al., 1998) and models (Ji and Smith, 1995; Bacmeister and Suarez, 2002).

By global angular momentum conservation, the surface stress influences the angular velocity of the earth. Indeed, one of the many global consequences of ENSO is an increase of the Earth's length of day due to an enhanced super rotation of the atmosphere during

\footnotetext{
* Corresponding author.

E-mail addresses: munnich@atmos.ucla.edu (M. Münnich), neelin@atmos.ucla.edu (J.D. Neelin).
} 
the peak phase of El Niño (Dickey et al., 1999; Hide and Dickey, 1991; Mo et al., 1997; Rosen et al., 1987). This has been attributed to changes in both northern hemisphere mountain torque and surface stress torque (Ponte et al., 1994; Ponte and Rosen, 1999; Wolf and Smith, 1987).

On time scales much longer than the spin-up of the atmospheric circulation on the order 2 weeks, one might expect the atmosphere to reach an equilibrium in which the total atmospheric angular momentum remains constant. On these time scales any change of momentum transfer in one region should thus be balanced by opposing changes elsewhere. Using both observational data and model results we shall show that such a balance holds to a large degree for ENSO anomalies. The structure of the resulting compensation of the surface stress within the tropics will be the focus of this note.

\section{Torque composite anomalies by surface stress}

Currently, no global observational surface stress data sets exist which cover both land and ocean, as needed for a budget of the torque anomalies during ENSO Thus, we must rely on model output or on model-based data assimilation such as that of the National Centers of Environmental Prediction (NCEP) reanalysis data set (Kalnay et al., 1996). A comparison of NCEP tropical Pacific stress with more direct observational, such as scatterometer data shows good agreement of these data sets in the main anomaly region along the equator (Chen, 2003). Nevertheless, deficiencies of the NCEP surface wind products have been noted ( $\mathrm{Wu}$ and Xie, 2003). One also has to bear in mind that the torque budget of reanalysis data can potentially have imbalances due to the assimilation procedure.

We, therefore, provide for comparison an analysis of an ensemble of four integrations of the atmospheric general circulation model (AGCM) model of the National Aeronautics and Space Administration's Inter-annual-to-Seasonal Prediction Project (NSIPP) (Bacmeister and Suarez, 2002). These data do not suffer from budget imbalances by data assimilation, and the use of an ensemble of integration provides better statistics. On the other hand, the link to ENSO depends entirely on the model-simulated response to specified sea surface temperatures (January 1930 through December 2000). Comparison to scatterometer stress and between NSIPP and NCEP momentum budgets is provided in Bacmeister and Suarez (2002). The NSIPP model has a uniform resolution of $2.5^{\circ}$ longitude, $2^{\circ}$ latitude and 34 unevenly spaced $\sigma$-levels in the vertical. Standard model output data on 17 pressure levels (surface to $10 \mathrm{mb}$ ) were used.

A composite of October through March surface torque in El Niño years (1972-1973, 1977-1978, 1982-1983, 1986-1987, 1991-1992, 1997-1998) minus La Niña years (1970-1971, 1973-1974, 1983-1984, 1988-1989, 1995-1996, 1998-1999) is shown for the NCEP reanalysis in Fig. 1a. The well-known ENSO anomaly (positive for El Niño) centered around the date line will here be referred to as the western Pacific anomaly (WPA). In the NCEP reanalysis, the WPA extends from $140^{\circ} \mathrm{W}$ to $140^{\circ} \mathrm{E}$, and from $5^{\circ} \mathrm{N}$ to $10^{\circ} \mathrm{S}$ with a tail to the south-east flanking the Southern Pacific Convection Zone (SPCZ). It is surrounded by negative anomalies in all directions. To the north and south an alternating pattern of negative and positive anomalies arcing to the east is visible. Not surprisingly in 


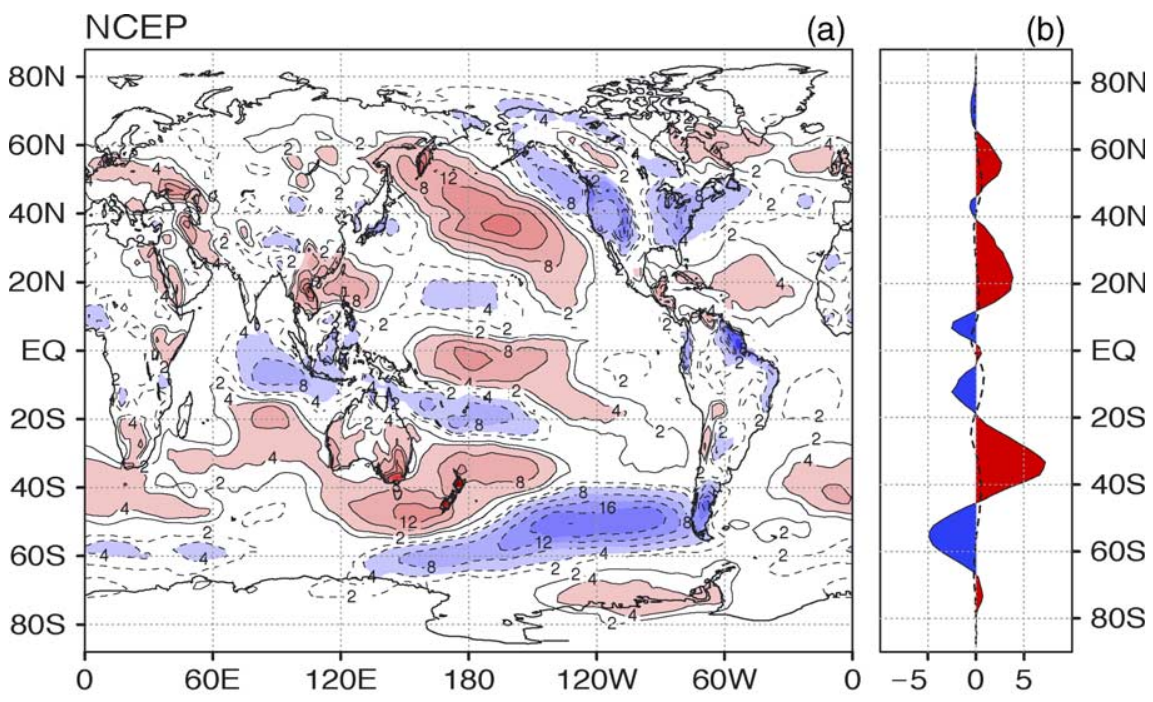

NSIPP

(c)

(d)

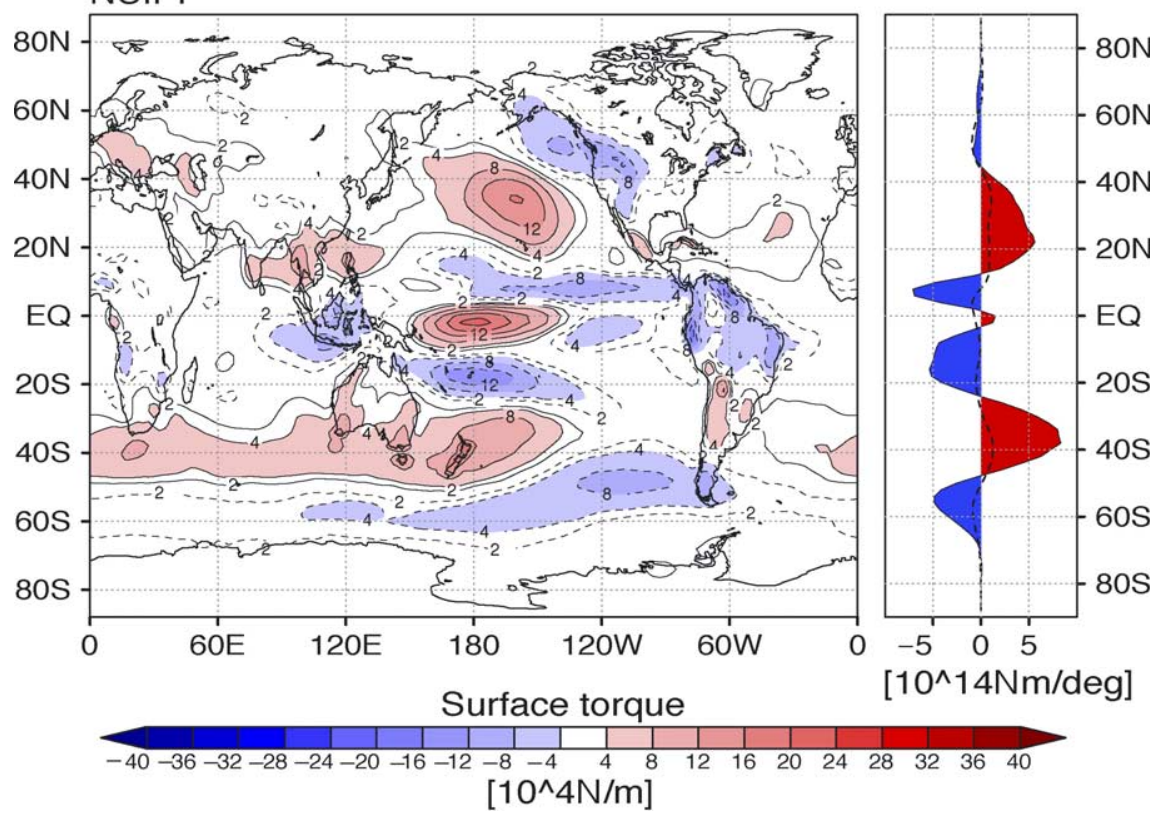

Fig. 1. Composite of six El Niño minus six La Niña October to March averages of (a) surface stress torque for NCEP reanalysis; (b) zonally integrated surface stress torque (solid) and local angular momentum change (dashed); (c) surface stress torque for NSIPP AGCM reanalysis; and (d) zonally integrated surface stress torque (solid) and local angular momentum change (dashed). Contour interval is $4 \times 10^{4} \mathrm{~N} / \mathrm{m}$ except zero contour is replaced by contours at $\pm 2 \times 10^{4} \mathrm{~N} / \mathrm{m}$. 
the northern hemisphere the pattern shows similarities to the well known Rossby-wave induced Pacific North American (PNA) pattern during ENSO, while the anomalies in the southern hemisphere are presumably associated with the less well established Pacific South American (PSA) pattern (Mo and Ghil, 1987; Karoly, 1989). To the west of the WPA, a strong negative anomaly appears over Indonesia and the eastern part of the equatorial Indian Ocean, while South-east Asia is covered by a positive torque anomaly. The higher surface drag over land gives rise to sharp peaks in the anomalies over land regions (South America, New Zealand, Australia, Indonesia, Southeast Asia and North America).

The anomalies of the NSIPP AGCM ensemble (Fig. 1c) are much stronger, but the general agreement with the NCEP reanalysis in the spatial pattern is quite remarkable. The WPA is centered exactly at the same location around the date line with the same northsouth and east-west extent, whereas the extension to the south-east along the SPCZ is missing. Again, the WPA is surrounded by negative anomalies. The anomaly to the east is stronger for NSIPP and the adjacent anomaly to the north peaks in lower latitudes and stretches eastward through the whole Intertropical Convergence Zone (ITCZ) to Central America. The pattern of alternating positive and negative anomalies associated with the PNA and PSA patterns are present as in the NCEP data.

The agreement of the general pattern in Fig. 1a and $\mathrm{c}$ is encouraging. We place greater confidence on the features for which the two data sets concur, and emphasize these aspects in the remainder of this article.

\section{Angular momentum balance}

The vertical integral of the zonal momentum equation over the whole atmospheric column can be expressed in an equation for the zonal angular momentum $M$ in the atmospheric column (See Ponte et al., 1994, who subsume the pressure gradient term in the flux vector.)

$$
\partial_{\mathrm{t}} M+\nabla \cdot \mathbf{F}=-\partial_{\lambda} P+\tau .
$$

Here $\lambda, \mathbf{F}, P$ and $\tau$ denote longitude, the zonal angular momentum flux vector, the integral of pressure over the atmospheric column and the total zonal surface torque, respectively. The latter is the sum of the surface, mountain and gravity wave torque. The surface torque, $\tau_{\mathrm{s}}=a \cos \phi \tau^{\lambda}$, is the torque due to zonal surface stress $\tau^{\lambda}$ acting on the earth's surface, where $a$ is the earth's radius and $\phi$ is latitude. The mountain torque $\tau_{\mathrm{m}}=-p_{\mathrm{s}} \partial_{\lambda} h$ occurs due to surface pressure $p_{\mathrm{s}}$ variation along the sloping topography $h$. In AGCMs, a third torque, the surface gravity wave torque $\tau_{\mathrm{g}}$, emerges from the parameterization of gravity waves excited by unresolved topographical features.

As outlined in the introduction, we expect the surface torque anomalies in one region to be balanced by anomalies of opposite sign in other regions on sufficiently long time scales. For seasonal (3-month) averages the anomalies in the local angular momentum change $\partial_{\mathrm{t}} M$ are not entirely negligible in Eq. (1). While the lead-lag relationship between this angular momentum change and surface torque has been extensively analyzed in other studies (Dickey et al., 1999; Ponte and Rosen, 1999), our focus is on the regional 
distribution and compensation of the surface torque. For a longer averaging interval of 6 months, we found that the local angular momentum changes $\left(\partial_{t} M\right)$ are an order of magnitude smaller than the other terms. A comparison of the zonal integral of the local angular momentum change with the integral of the surface torque is given in Fig. $1 \mathrm{~b}$ and $\mathrm{d}$ for illustration. For such zonal integrals (denoted by brackets) the pressure term drops out and, with $\partial_{t} M$ negligible, Eq. (1) reduces to a balance between angular momentum export and the surface torques

$$
\frac{1}{a \cos \phi} \partial_{\phi}\left(\cos \phi\left[F^{\phi}\right]\right)=\left[\tau_{\mathrm{s}}\right]+\left[\tau_{\mathrm{m}}\right]+\left[\tau_{\mathrm{g}}\right] .
$$

Our analysis will focus on how regional contributions to the surface torque tend to add or cancel in the zonal averages, hence to what extent the familiar ENSO patterns are balanced by meridional momentum export $F^{\phi}$. The most important torque contributions, surface stress and mountain torque, will be presented here. In NCEP data, the gravity wave torque anomaly, while not entirely negligible in latitude bands with significant topography, is generally weak. Its influence will be mentioned in the text where relevant. Note that Huang et al. (1999) make a convincing case, based on analysis of NCEP reanalysis data, that current parameterizations overestimate gravity wave torque in most seasons. This suggests an even weaker influence of gravity wave torque anomalies than estimates from NCEP data. Surface gravity wave torque for the NSIPP model is not available.

\section{Tropical torque budgets}

Fig. 2 shows the sum of surface stress and mountain torque together with the latitude bands and subregions chosen in our budget analysis. The surface torque budget for these bands is shown in Fig. 3 .

The latitude band $3^{\circ} \mathrm{S}-3^{\circ} \mathrm{N}$ is of interest because it corresponds to the oceanic wave guide crucial for ENSO. For NSIPP (Figs. $2 \mathrm{c}$ and $3 \mathrm{e}$ ), the positive WPA $\left(155^{\circ} \mathrm{E}-135^{\circ} \mathrm{W}\right)$ is flanked by negative anomalies over the eastern Pacific, Indonesian subcontinent and the Indian ocean (Fig. 2c). Further to the east, South America is covered by negative anomalies, which peak near the Atlantic and Pacific coasts. The total torque due to the negative torque anomalies in the equatorial band is slightly larger than the positive torque of the WPA (Fig. 3e). From this, we infer by Eq. (2) that there can be only little net export of positive (eastward) angular momentum out of this latitude band.

For the NCEP data (Figs. 2a and 3a), the eastern Pacific anomalies are rather weak. South America alone cancels for most of the WPA, with mountain torque and surface stress torque contributing equally to the negative anomaly (Fig. 3a). The anomalies over Indonesia and the eastern Pacific are small. Another sizable negative anomaly over the eastern Indian Ocean leads to an overall negative anomaly in the equatorial band. Overall, like NSIPP the NCEP data budget implies a slight export of positive angular momentum out of the equatorial band. For the NCEP reanalysis gravity wave torque over the Andes is negative and thus increases the inferred export.

If we widen the latitude band to $10^{\circ} \mathrm{S}$ to incorporate the whole of the WPA (Fig. $3 \mathrm{~b}$ and f), the size of the compensating negative anomalies in the latitude band increases relative to 

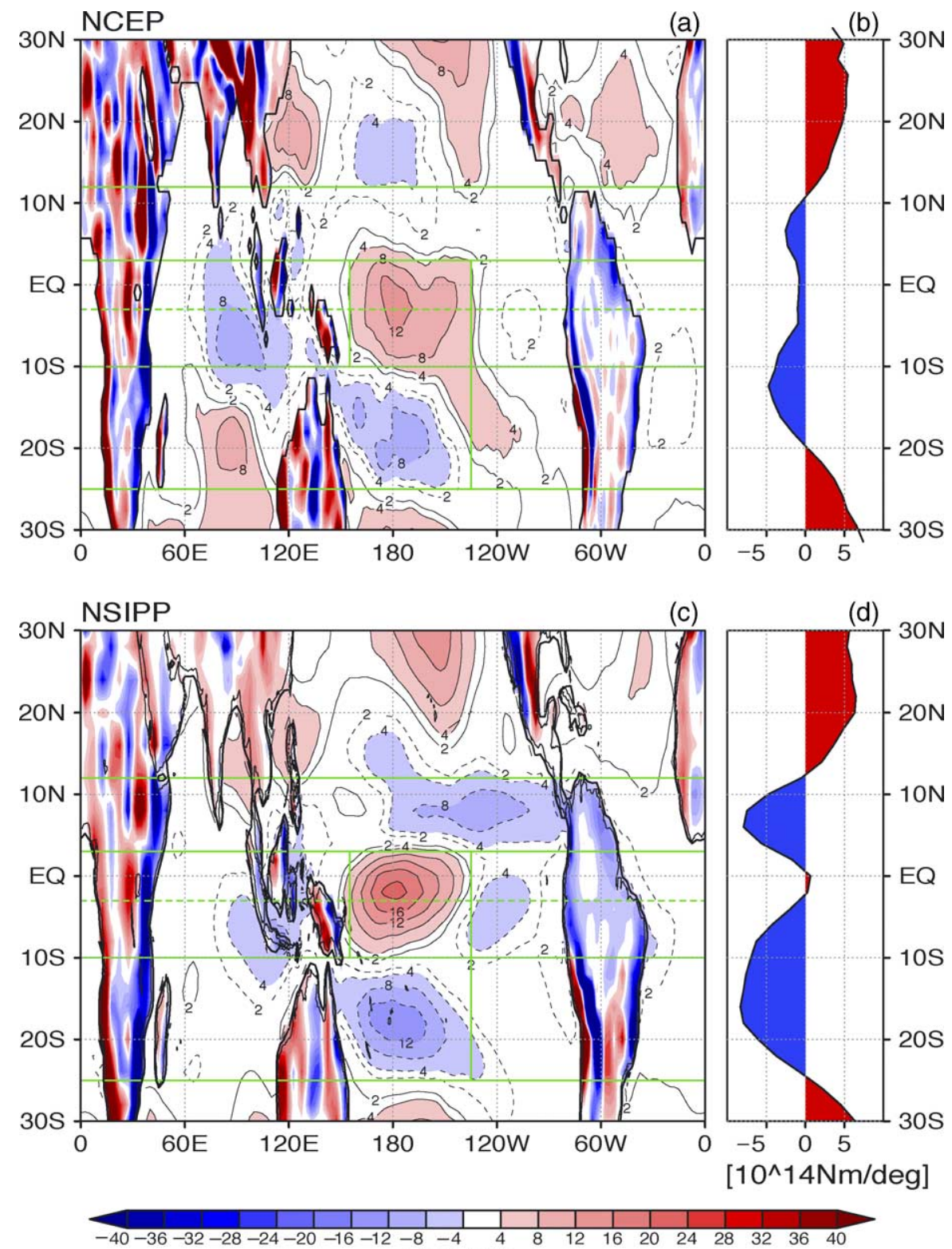

$\left[10^{\wedge} 4 \mathrm{~N} / \mathrm{m}\right]$

Fig. 2. (a) Sum of surface stress torque and continental mountain torque for NCEP reanalysis and (c) sum of surface stress torque and continental mountain torque for NSIPP AGCM reanalysis. The green lines indicate latitude bands and selected longitude delimiters used in the budget analysis. (b, d) Zonally integrated sum of surface torque and mountain torque for NCEP reanalysis and NSIPP AGCM, respectively. 


\section{NCEP}

(a) $\quad 3 \mathrm{~S}-3 \mathrm{~N}$

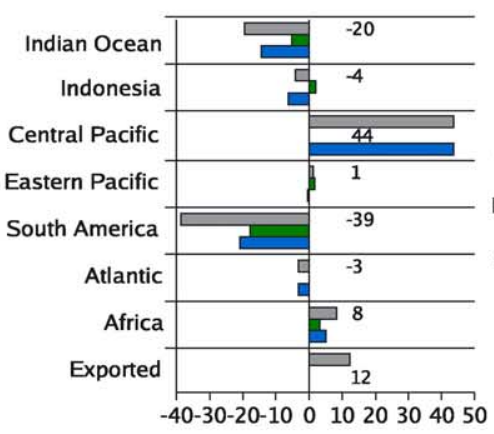

(c) $25 \mathrm{~S}-10 \mathrm{~S}$

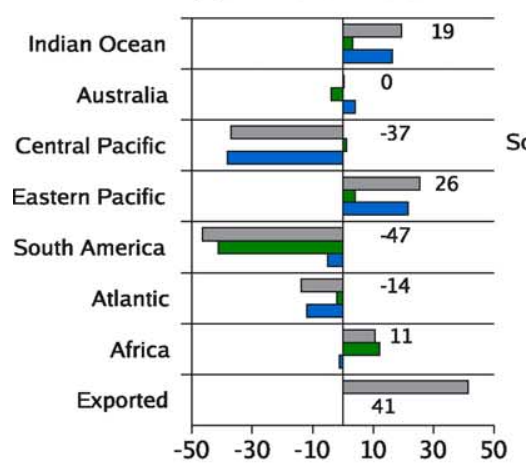

(b) $\quad 10 \mathrm{~S}-3 \mathrm{~N}$

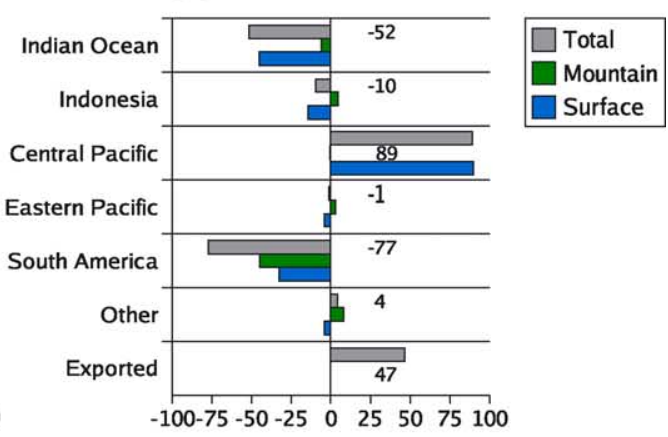

(d) $3 \mathrm{~N}-12 \mathrm{~N}$

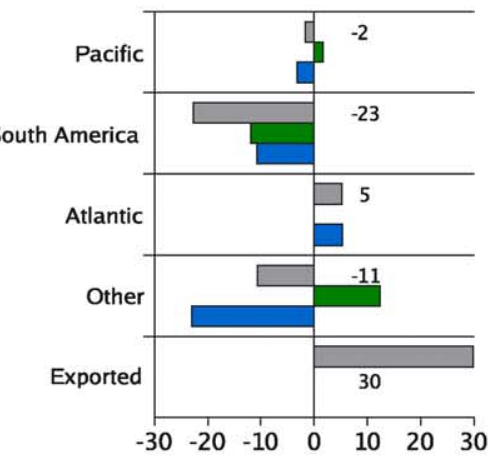

NSIPP

(e) $3 \mathrm{~S}-3 \mathrm{~N}$

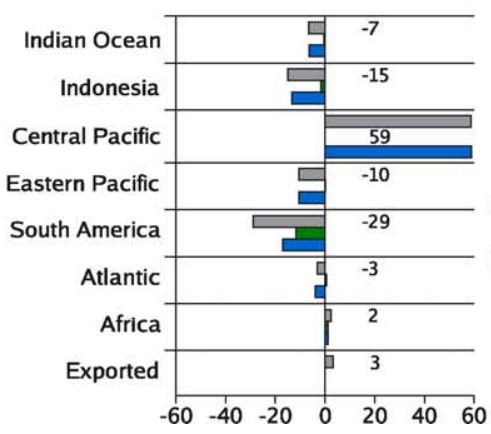

(f) $\quad 10 \mathrm{~S}-3 \mathrm{~N}$

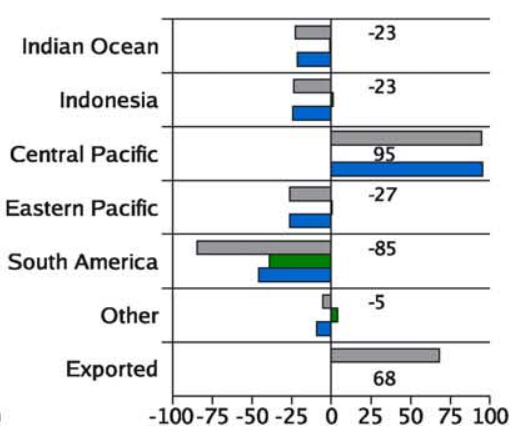

Fig. 3. Areal mountain torque (green), surface stress torque (blue) and total torque (gray) for various latitude bands in $10^{14} \mathrm{Nm}$. NCEP reanalysis (a)-(d); NSIPP AGCM (e)-(h). For NCEP, the mountain torque over the ocean is non-zero due to spectral representation of topography. 
(g) $25 \mathrm{~S}-10 \mathrm{~S}$

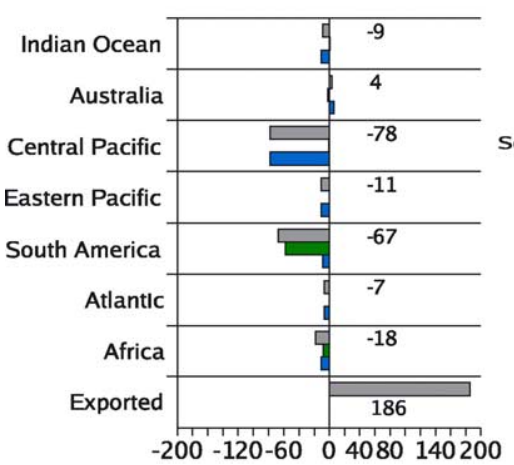

(h) $3 \mathrm{~N}-12 \mathrm{~N}$

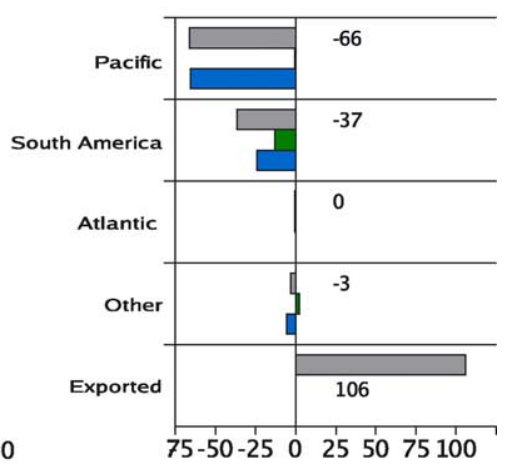

Fig. 3 (continued)

the WPA in both NCEP and NSIPP data. Thus, this latitude band must experience a substantial export of eastward momentum.

Further to the south, the positive equatorial stress anomaly in the central Pacific is mirrored by a slightly weaker negative anomaly centered over the Fiji Islands, which extends to about $25^{\circ} \mathrm{S}$ (Fig. 2). Considering the balance in this $10^{\circ} \mathrm{S}-25^{\circ} \mathrm{S}$ latitude band in the NCEP reanalysis (Fig. 3c), this western Pacific negative anomaly is balanced by positive anomalies over the Indian and the eastern Pacific. A large negative mountain torque over the Andes and some negative surface stress anomalies over the Atlantic give rise to net export of eastward momentum. Large negative anomalies are also present over South America and the Western Pacific in this latitude band in the NSIPP data (Fig. $3 \mathrm{~g}$ ). The contributions from other regions are weaker, implying a stronger export of eastward momentum.

In the NSIPP data, the north Pacific ITCZ $\left(3^{\circ} \mathrm{N}-12^{\circ} \mathrm{N}\right)$ region is covered by strong negative torque anomalies in the Pacific and South America (Figs. 2c and $3 \mathrm{~h}$ ). Since no balancing torques exists in this latitude band a large export of eastward momentum is implied (Fig. 3h). The South American negative anomalies are also present in the NCEP data (Figs. 2a and 3d). However, the negative anomalies in the tropical north Pacific are located further to the north and the anomalies along the ITCZ are absent, meaning that the inferred eastward momentum export is smaller for the reanalysis data (Fig. 3d).

\section{Discussion and conclusions}

The analysis of the ENSO related wind stress pattern presented here focuses on the regional distribution of the associated torque anomalies, as well as the amount of cancellation between different regions and within tropical latitude bands. It complements previous studies which focused on the associated observed atmospheric angular momentum changes and their causes.

For ENSO, the time derivative of angular momentum is not negligible in the torque budget for seasonal means, but for 6-month averages a balance among surface torque and momentum transports is established. Gravity wave drag plays a minor role whereas 
mountain torques contribute significantly and must be considered along with the leading surface stress torque.

Torque budgets are considered for tropical latitude bands. For $3^{\circ} \mathrm{N}-3^{\circ} \mathrm{S}$, corresponding to the oceanic equatorial wave guide, torque from the positive surface stress anomalies in the western Pacific is strongly compensated by negative torque anomalies in other regions. For $10^{\circ} \mathrm{S}-3^{\circ} \mathrm{N}$, corresponding to the latitude extent of the positive El Niño stress anomalies over the western Pacific, similar compensation holds, although to a lesser degree. The compensation of the negative anomalies in the latitude bands $25^{\circ} \mathrm{S}-10^{\circ} \mathrm{S}$ and $3^{\circ} \mathrm{N}-12^{\circ} \mathrm{N}$ is either weak or absent, so that by angular momentum conservation these latitude bands must export a sizable amount of positive (eastward) momentum to higher latitudes. It thus appears plausible to regard the negative torque anomalies in these bands as a footprint of the active role of these regions in the observed ENSO teleconnections to midlatitudes.

Negative surface and mountain torque anomalies over South America play an important role in the torque budgets in all latitude bands. For instance, the strongest torque compensating the central Pacific positive torque occurs over South America. If South America did not provide this contribution, then either angular momentum would be exported from the equatorial band or the eastward teleconnections from the Pacific would have to produce additional stress over the Atlantic and other regions to the east. It may thus be conjectured that South American surface and mountain drag must play a role in teleconnections: either affecting momentum export to higher latitudes or, more likely, acting as a 'barrier' for ENSO teleconnections to the tropical Atlantic.

\section{Acknowledgements}

This research was sponsored by the National Oceanic and Atmospheric Administration through grants NA16GP2003 and NA16GP2004 and by the National Aeronautics and Space Administration (NASA) through grant NAG5-9358. We thank the NSIPP project team members for access to the NSIPP data.

\section{References}

Bacmeister, J.T., Suarez, M.J., 2002. Wind stress simulations and the equatorial momentum budget in an AGCM. J. Atmos. Sci. 59, 3051-3073.

Chen, D., 2003. A comparison of wind products in the context of ENSO prediction. Geophys. Res. Lett. 30 (3), 1107.

Deser, C., Wallace, J.M., 1990. Large-scale atmospheric circulation features of warm and cold episodes in the tropical Pacific. J. Clim. 3, 1254-1280.

Dickey, J.O., Gegout, P., Marcus, S.L., 1999. Earth-atmosphere angular momentum exchange and ENSO: the rotational signature of the 1997-98 event. J. Geophys. Res. 26, 2477-2480.

Harrison, D.E., Larkin, N.K., 1998. El Niño-Southern Oscillation sea surface temperature and wind anomalies, 1946-1993. Rev. Geophys. 36, 353-400.

Hide, R., Dickey, J.O., 1991. The earth's variable rotation. Science 253, 629-637.

Huang, H.-P., Sardeshmukh, P.D., Weickmann, K.M., 1999. The balance of global angular momentum in a longterm atmospheric data set. J. Geophys. Res. 104, 2031-2040. 
Ji, M., Smith, T.M., 1995. Ocean model responses to temperature data assimilation and varying surface wind stress: intercomparisons and implications for climate forecast. Mon. Wea. Rev. 123, 1811-1821.

Kalnay, et al., 1996. The NCEP/NCAR 40-Year reanalysis project. Bull. Amer. Meteor. Soc. 106, 447-462.

Karoly, D.J., 1989. Southern hemisphere circulation features associated with El Niño-Southern Oscillation events. J. Clim. 2, 1239-1252.

Mo, K.C., Ghil, M., 1987. : Statistics and dynamics of persistent anomalies. J. Atmos. Sci. 44, 877-902.

Mo, K.C., Dickey, J.O., Marcus, S.L., 1997. Interannual fluctuations in atmospheric angular momentum simulated by the national centers for environmental prediction medium range forecast model. J. Geophys. Res. 102, 6703-6713.

Ponte, R.M., Rosen, R.D., 1999. Torques responsible for evolution of atmospheric angular momentum during the 1982-83 El Niño. J. Atmos. Sci. 56, 3457-3462.

Ponte, R.M., Rosen, R.D., Boer, G.B., 1994. Angular momentum and torque in a simulation of the atmosphere's response to the 1982-83 El Niño. J. Clim. 7, 538-550.

Rasmusson, E.M., Carpenter, T.H., 1983. Variations in tropical sea surface temperature and surface wind fields associated with the Southern Oscillation/El Niño. Mon. Wea. Rev. 110, 354-384.

Rosen, R.D., et al., 1987. Medium-range numerical forecast of atmospheric angular momentum. Mon. Wea. Rev. $115,2170-2175$.

Wallace, J.M., Rasmusson, E.M., Mitchell, T.P., Kousky, V.E., Sarachik, E.S., von Storch, H., 1998. On the structure and evolution of ENSO related climate variability in the tropical Pacific: Lessons from TOGA. J. Geophys. Res. 14, 241-259.

Wolf, W.I., Smith, R.B., 1987. : Length-of-day changes and mountain torque during El Niño. J. Atmos. Sci. 44 , 3656-3660.

Wu, R., Xie, S.P., 2003. On equatorial pacific surface wind changes around 1977: NCEP-NCAR reanalysis versus COADS observations. J. Clim. 16, 167-173. 